\title{
SSynthesis
}

International Scientific Conference of IT and Business-Related Research

\section{CENOVNA KOMUNIKACIJA SA POTROŠAČIMA}

\section{PRICE COMMUNICATION WITH CONSUMERS}

\author{
Sveto Veselinović \\ Univerzitet Sinergija, Bijeljina, Republika Srpska
}

\begin{abstract}
Apstrakt:
Svedoci smo sveopšte globalizacije i internacionalizacije svetske privrede u kojoj organizacije kroz razne oblike komuniciranja sa potrošačima pokušavaju zauzeti svoje mesto na tržištu, doprinoseći tako stvaranju sveopšteg promocionog haosa u kome jedni uspevaju a drugi uzaludno troše i bacaju svoj novac. Cilj ovog rada je da ukaže na značaj cene kao faktora komuniciranja sa potrošačima, koja predstavlja ključ potrošačeve konačne odluke. Cena sve više kod potrošača predstavlja indikator kvaliteta proizvoda i usluge. Firme preko cene ističu svoj imidž i pozicioniraju se na tržištu stvaranjem diferencijalne prednosti. Potrošači cenom pokazuju svoj snobizam, ističu željeni status u društvu, ili pak smanjuju kupovni rizik. U radu su analizirane neke od metoda cenovnog komuniciranja sa potrošačima, stavljanjem posebnog akcenta na komunikaciju cenama novih prizvoda, linije proizvoda, kao i psihološko komuniciranje cenama. Centralni deo ovog rada je poruka da savremeni potrošač sve više značaja pridaje funkcionalnim elementima komunikacije u kojima cena, dobro uklopljena sa ostalim elementima marketinškog miksa, igra značajnu ulogu u procesu donošenja odluke. Uticaj interneta i digitalne tehnologije još više je pojačao značaj cene kao faktora konačnog donošenja odluke. Izvedeni zaključci su dobiveni generalizacijom, deduktivnim metodom analize pisanog materijala i komparativnom analizom marketing strategija različitih organizacija.
\end{abstract}

\section{Ključne reči:}

simbolička komunikacija, funkcionalna komunikacija, percepcija cena, psihološko formiranje cena.

\section{UVOD}

Čovek kao društveno biće poseduje obeležje govornog ponašanja kao oruđa za saopštavanje svojih misli osećanja i namera, što ga odvaja od ostalih živih bića. Osnovu međusobnog komuniciranja ljudi čini jezik. U tom smislu komunikacija se može definisati kao razmena značenja među ljudima koju pored govora čine i svi drugi simboli duha sa sredstvima njihovog prenošenja u prostoru i njihovog očuvanja u vremenu. Danas se više ne postavlja pitanje da li organizacije treba da komuniciraju sa potrošačima, jer „proizvoditi a ne reklamirati se je isto što i namigivati devojci u mraku“. Ključno pitanje je koji oblik i formu komunikacije primeniti da bi postigli največi uticaj na potrošačevu konačnu odluku u kupovini. Savremene organizacije u komuniciranju sa potrošačima pored simboličkog komuniciranja, kroz prenošenje misli, ideja i emocija kojima izaziva željene reakcije kod potrošača, sve češće koriste funkcionalne

\section{Abstract:}

We are witnessing general globalization and internationalization of the world economy in which organizations attempt to find their place in the market through implementing various forms of communication with consumers, thus contributing to the creation of universal promotional chaos in which some succeed while others waste their money. The purpose of this paper is to highlight the importance of price as a factor of communication with consumers, which has a considerable impact on consumers when making their final decision. Consumers are increasingly more perceiving the price as the key indicator of the quality of goods and services. Companies use it to promote their image and adequately position themselves in the market by creating differential advantage. Consumers use price to show their snobbism, emphasize the desirable social status, or decrease purchasing risk. The paper analyses some of the methods of price communication with consumers, with special emphasis placed on communication through new product prices, product lines, as well as the psychological price communication. The key segment of this paper is the message that a contemporary consumer assigns more importance to fictional elements of communication where price, if well-incorporated into other elements of marketing mix, plays an important role in the decisionmaking process. The impact of the Internet and digital technology has further strengthened the importance of price as the crucial factor for making the final decision. Conclusions have been reached by means of generalization, deductive method of written material analysis and comparative analysis of marketing strategies used by various organizations.

\section{Key words:}

symbolic communication, functional communication, price perception, psychological price formation.

elemente komuniciranja. Funkcionalna komunikacija obavlja se pomoću instrumenata marketing miksa - prozvoda, cene i distribucije. U daljem tekstu ovog rada bavićemo se cenom kao faktorom komunikacije sa potrošačima, ali ne smemo zaboraviti da samo cena uklopljena u necenovne faktore marketing miksa obezbeđuje dugoročno pozitivnu komunikaciju sa potrošačima (Jobber \& Fahy, 2006).

Između cene i necenovnih faktora marketing miksa (proizvod, promocija i distribucija) postoji visok stepen međuzavisnosti, stoga se ni uticaj necenovnih faktora na ponašanje potrošača ne može izdvojeno pratiti bez njegovih odnosa sa cenom proizvoda. Samo dobro odmerena prodajna cena proizvoda može pružiti adekvatnu i uspešnu primenu necenovnih faktora u cilju stimulisanja potrošača na kupovinu. Isto tako, bez adekvatne i dobre primene necenovnih faktora, samo povećanje ili smanjenje cena proizvoda neće dati prave efekte i rezultate uticaja na potrošače. Sa aspekta marketinga cena predstavlja 
element marketing strategije čiji cilj nije maksimalna ili najviša moguća cena, nego pokrivanje troškova i ostvarenje određenog dohotka uz istovremeno prilagođavanje percipiranoj vrednosti proizvoda od strane potrošača. Preterano niske cene dovode do gubitka marže, dok preterano visoke cene dovode do gubitka prodaje. I jedne i druge ugrožavaju profitabilnost kompanije i dovode do gubitaka. Potrošač, shodno svojim psihološkim faktorima rasuđivanja, u zavisnosti od specifičnosti proizvoda, cenovne elastičnosti potražnje, imidža proizvoda ili proizvođača, specifičnosti kanala distribucije i niza drugih faktora percipira koja je to „fer“ cena za određeni proizvod. Pri donošenju odluke o cenama preduzeće mora nastojati da sa jedne strane cena bude prihvatljiva za potrošača, a sa druge strane da se ostvari profit. Ti ciljevi su često u međusobnom konfliktu. Stoga je pravilno formiranje i upravljanje cenama, kao integralnim delom strategije preduzeća, presudna aktivnost koja utiče na profitabilnost jedne kompanije. (Morno, 1990.)

\section{METODI CENOVNOG KOMUNICIRANJA SA POTROŠAČIMA}

Savremene organizacije, dakle, putem cena komuniciraju sa ciljnim segmentima potrošača. One cenom potrošaču mogu da šalju informacije o kvalitetu proizvoda, imidžu firme, ističu potrošačev željeni status, snobizam, nizak kupovni rizik i sl. Shodno ciljevima komuniciranja proizvođači cene mogu koristiti kao sredstvo diferenciranja proizvoda i zadovoljavanja informativnih i psiholoških potreba potrošača. Za koje će se cene organizacija opredeliti ovisi o njenoj marketing strategiji koja se koristi kao podrška proizvodu.

Mikroekonomska analiza cenovne elastičnosti nam govori da bi cenu određenog proizvoda trebalo odrediti u tački preseka (jednakosti) marginalnih (dodatnih) vrednosti troškova i potražnje. S obzirom da funkcije potražnje i troškova u stvarnosti nisu dostupne u praksi se iskristalisalo više načina određivanja cena shodno strategijskim ciljevima organizacije i uslovima na tržištu. Tako cene mogu biti zasnovane na troškovima organizacije kao faktoru koji određuje iznos specifične (minimalne) cene po kojoj se proizvodi i usluge mogu realizovati na tržištu da bi se pokrili troškovi. Drugi metod je formiranje cena orijentisano prema konkurenciji. Ovde se najveća pažnja daje visini cene koju je odredila konkurencija i odnosu naše cene prema konkurentskoj (ista, manja, veća), shodno poziciji koju gradimo. Treći pristup formiranja cene je pod uticajem tržišta i podrazumeva procenu vrednosti koju proizvod ima za kupce. Ukratko, što je veća vrednost koju proizvod nudi u poređenju sa konkurencijom to je veća cena koju može da naplati (Milisavljević, 2010). Pored ovih metoda ili u kombinaciji sa njima organizacije koriste i niz metoda psihološki formiranih cena koristeći persuazivne elemente komunikacije sa potrošačima. Naravno, u svim ovim metodama mora se voditi računa o tome da li je moguće sa aspekta troškova prodavati proizvode po takvoj ceni.

\subsection{KOMUNIKACIJA CENAMA NOVIH PROIZVODA}

Da bi se omogućila uspešna prodaja novog proizvoda na tržištu i obezbedila zaštita imitacije od drugih preduzeća neophodno je definisati željenu politiku, ciljeve i strategiju novog proizvoda odgovarajućom kombinacijom cene sa ostalim necenovnim instrumentima marketing miksa (proizvod, distribucija, promocija). Što je stepen noviteta proizvoda veći to je veća i sloboda koju preduzeće ima pri formiranju tržišne cene. Ukoliko se radi o bitnoj i suštinskoj inovaciji onda preduzeće ostvaruje monopolsku strukturu tržišta za svoj proizvod. Pri definisanju cene novog proizvoda treba imati u vidu tri cilja:
1) da proizvod bude prihvaćen od potrošača, 2) da se proizvod zadrži na tržištu i pored rastuće konkurencije i 3) da se ostvari dobit. (Milisavljević, 2010)

Usklađivanjem cena sa strategijom komuniciranja na tržištu (promocijom) dobijamo matricu četiri marketing strategije. Slika 1.

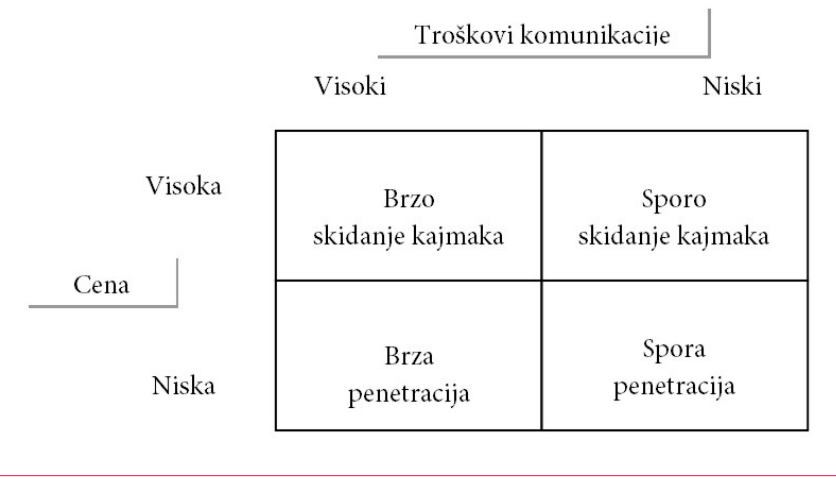

Slika 1. Strategija komuniciranja novim proizvodom Izvor: (Jobber \& Fahy, 2006)

Ukoliko se radi o velikom stepenu noviteta na proizvodu i visokom stepenu potražnje za proizvodom, organizacije koriste strategiju visokih cena, i visokih troškova komunikacije odnosno „brzog skidanja kajmaka“. Ova strategija podrazumeva jaku tržišnu komunikaciju kojom organizacija stvara visok nivo svesti i znanja o proizvodu. Cilj organizacije je u što kraćem periodu, pre pojave konkurencije na tržištu, ostvariti visoke prinose na investicije. Ukoliko je otežan ulazak novih konkurenata na tržište (tehnološke, finansijske i pravne prepreke) ili priroda proizvoda ne zahteva jaku tržišnu komunikaciju, organizacije mogu da koriste strategiju visokih cena i niskih troškova komunikacije, odnosno „sporog skidanja kajmaka“. Prihvatanjem visoke cene od strane kupaca kao znak kvaliteta proizvoda koje vredi platiti, organizacija nastavlja sa visokim cenama sa ciljem podsticaja takvog kupčevog verovanja. Problemi visokih cena nastaju u kasnijim fazama životnog ciklusa proizvoda kada se na tržištu pojavi konkurencija i dođe do zasićenja tržišta. Svako naglo smanjivanje cena može izazvati sumnju potrošača u kvalitet i dovesti do gubitka tržišta. U takvim uslovima bolja rešenja su razvijanje novih tehnoloških rešenja i poboljšanje kvaliteta, dizajna, pakovanja, adekvatnih komunikacijskih varijabli i sl. Organizacije koje kombinuju niske cene proizvoda i visoke troškove komunikacije teže brzoj penetraciji tržišta. Cilj ove strategije je brz dolazak do većeg tržišnog učešća (dominacije na tržištu). Poslednja strategija primenjuje nisku cenu i malo komunikaciono učešće na tržištu, odnosno „strategiju spore penetracije“. Spore penetracije tržišta primenjuju privatni brendovi kojima nije neophodna promocija da bi ostvarili učešće na tržištu, a niski troškovi promocije doprinose održavanju visokih profitnih marži. Formiranje niske cene nosi sa sobom rizik percepcije potrošača o slabom kvalitetu ponuđenog proizvoda ili usluge. Sa aspekta komunikacije penetracijska cena nema posebno značenje osim prenošenja informacije o "pravedno formiranoj ceni“ u skladu sa ponuđenom vrednošću proizvoda i apelovanja na nizak kupovni rizik. Međutim, kod skupih i luksuznih proizvoda sa dominantnim rizikom kupovine, zbog visokog stepena variranja kvaliteta među različitim markama, potrošači se najčešće oslanjaju na cenu kao pokazatelj vrednosti i faktor smanjenja kupovnog rizika, premda stvarna razlika između proizvoda ne mora ni postojati. Kada je u pitanju proizvod koji se kupuje kao poklon, visoka cena pored smanjenja kupovnog rizika, povećava samopouzdanje i imidž darivaoca. 


\subsection{CENOVNA KOMUNIKACIJA KVALITETOM PROIZVODA}

Međutim, ukoliko preduzeće teži dugoročnom opstanku na određenom tržištu nužno mora uvažiti činjenicu da kvalitet proizvoda bitno determiniše strategiju formiranja cena. $U$ tom smislu moguća je primena neke od dole navedenih strategija (Slika 2). segmenata potrošača. Tako je postalo normalno da proizvođači trajnih potrošnih dobara imaju u svom proizvodnom programu poluautomatske i automatske modele, standardne, de-luxe i super de-luxe modele bazično istog proizvoda. Odnos među cenama pojedinih modela ne sme biti baziran samo na troškovima nego i na tražnji i konkurenciji. Određivanje cena pojedinih modela determinisano je delovima tržišta kojima su namenjeni, kao i karakteristikama i cenama sličnih modela konkurentskih preduzeća. U izraženoj konkurentskoj situaciji preduzeće nema mogućnost formiranja vlastite cene nego mora da se uklapa u okvire cena koje su za pojedine modele postale uobičajene, shodno razmišljanjima i vrednovanju od strane kupaca. Pojedine kompanije u borbi sa jeftinim konkurentskim proizvodima lansiraju na tržište svoje jeftine „brendove borce" sa ciljem zadržavanja imidža i profitnih marži postojećih marki (Kompanija Apple je lansirala na tržište kompjuter Mac Mini da bi se takmičila sa jeftinim računarima iz Kine. Proizvodnjom niza proizvoda koji se prodaju po različitim cenama organizacije prevazilaze prepreku cenovne osetljivosti potrošača navodeći ih tako na kupovinu skupih proizvoda sa velikim profitnim maržama (Jobber \& Fahy, 2006).

Definisane cene u odnosu na kvalitet proizvoda mogu biti: precenjene, podcenjene i primenjene kvalitetu proizvoda. Strategije cena koje nisu u skladu sa kvalitetom proizvoda, već su znatno veće, obeležene su brojevima 4, 7 i 8. Ovakva strategija cena može biti prihvatlijiva u izuzetnim prilikama (specijalizovani proizvodi i usluge) ali po pravilu je treba izbegavati na duži rok. Strategije cena 2, 3 i 6 spadaju u izuzetno povoljne cene za kupce, jer dobijaju jako kvalitetne proizvode po niskim cenama. Ove cene su sa strane proizvođača nepovoljne, jer donose nisku profitabilnost i ne preporučuju se na duži rok. Koriste se u situacijama ulaska na novo tržište na kome dominira jaka konkurencija. Strategije 1, 5 i 9 zadovoljavaju interese i proizvođača i kupaca, na ovim strategijama nema gubitnika, svi dobijaju i stoga su dugoročno najpovoljnije i jedino prihvatljive. Proizvod i cena su u skladu, adekvatan kvalitet proizvoda prati odgovarajuća adekvatna cena. Prvom strategijom se potrošaču nudi vrhunski proizvod po izuzezno visokoj ceni, peta strategija daje proizvod prosečnog kvaliteta po isto tako prosečnim i umerenim cenama, a strategija 9 nudi proizvode niskog kvaliteta po izuzetno niskim cenama (Poljić, 2007).

\subsection{KOMUNIKACIJA CENAMA LINIJE PROIZVODA}

Retke su organizacije koje proizvode samo jedan ili manji broj proizvoda. Realnost poslovanja savremenih organizacija ogleda se u proizvodnji čitave palete proizvoda. Divezifikacija proizvodnog programa predstavlja ključ njihovog uspeha. U takvim situacijama preduzeća pri formiranju cena moraju doneti odluku ne samo o bazičnoj ceni proizvoda, nego i o međusobnom odnosu cena pojedinih proizvoda koji čine njegovu proizvodnu liniju. Preduzeće sa širokim proizvodnim programom proizvoda nema veliku slobodu manipulisanja sa strukturom cena. Ono ne sme narušiti međusobni odnos cena proizvoda u proizvodnom programu, ali zato ima mogućnost manipulisanja sa alokacijom opštih troškova i dobiti po proizvodima. Širok proizvodni asortiman (od relativno niskog kvaliteta i cene, do relativno visokog kvaliteta i cene) daje mogućnost preduzeću da iskoristi različitu elastičnost tražnje na pojedinim delovima tržišta i svojim spektrom ponude zadovolji potrebe različitih ciljnih
Određivanje cena linije proizvoda nosi sa sobom veliki rizik greške u vrednovanju pojedinog proizvoda. Ukoliko kupac percipira da je cena proizvoda visoka u odnosu na ponuđeni kvalitet, on može takav stav preneti na celu proizvodnu liniju tog preduzeća. Naravno, može se desiti i obrnuto, poželjna svojstva i dobro određena cena nekog proizvoda mogu se pozitivno preneti i na ostale proizvode iz ponuđene linije proizvoda organizacije. Ova sposobnost ljudskog uopštavanja (generalizacije) proizvoda omogućila je organizacijama razvoj familijarnih brendova sa jedinstvenom promocijom i distribucijom što u znatnoj meri smanjuje troškove poslovanja i omogućava formiranje kurentnih tržišnih cena.

\subsection{PSIHOLOŠKE KOMPONENTE CENOVNE KOMUNIKACIJE}

Cena je moćno sredstvo pozicioniranja proizvoda na tržištu. Ona za mnoge potrošače predstavlja indikator kvaliteta. Posebno je to slučaj kod onih proizvoda čiji kvalitet ne može objektivno da se izmeri (pića, parfemi, luksuzni proizvodi, kompleksni proizvodi trajne vrednosti i sl.). Ti proizvodi za potrošače najčešće imaju imaginarnu vrednost koja se ne može vrednovati racionalno. Pojedini potrošači koriste visoku cenu proizvoda kao sredstvo za izražavanje statusa i ugleda u društvu. Proizvod s prestižnim kvalitetom i poznatom markom potrošači doživljavaju i očekuju da bude skuplji od drugih proizvoda iste namene. Na taj način oni žele istaći svoj društveni rang i status. Njih jednostavno ne zanimaju jeftini proizvodi koje svako može kupiti. Drugi opet visokim cenama proizvoda leče nedostatak samouverenosti i osiguravaju pojačanje vlastitog samopouzdanja (Maričić, 2011).

Također, mehanizam delovanja povećanja ili sniženja cena ne odražava se na potrošače linearno i željenom projekcijom. Potrošači svoju odluku o kupovini ne donose samo na temelju promena cena što proizvođači i trgovci često ili ne znaju ili ignorišu. Percepcija povećanja ili smanjenja cena igra, čini se, bitnu ulogu u njihovom ponašanju. Povećanje ili smanjenje cene nekog proizvoda potrošači mogu participirati na pozitivan ili negativan način. Neki od načina percepcije promene cena 
prikazani su u tabela broj 1 (Gutić, 2009). Da bi izbegle posledice pogrešnog percipiranja promene cena, organizacije moraju dobro odmeriti obeležja potrošača, proizvoda, stanje konkurencije te kvalitet ostalih elemenata marketing miksa koji determinišu nivo cena na tržištu.

\begin{tabular}{|c|c|}
\hline \multicolumn{2}{|r|}{$\begin{array}{l}\text { Kako potrošači percipiraju } \\
\text { povećanje ili smanjenje cene proizvoda? }\end{array}$} \\
\hline $\begin{array}{c}\text { Promena } \\
\text { cene }\end{array}$ & Percepcija cene \\
\hline \multirow[b]{2}{*}{$\begin{array}{l}\text { Povećanje } \\
\text { cene }\end{array}$} & $\begin{array}{l}\text { Moguće negativne konotacije } \\
\text { Prodavači se žele na brzinu obogatiti } \\
\text { Taj se proizvod očito loše prodaje i malo traži, pa } \\
\text { prodavači putem više cene žele to nadoknaditi } \\
\text { Sami su na tř̌ištu, pa mogu raditi što ih volja } \\
\text { Bez tog proizvoda ne mogu, pa ga moram kupiti } \\
\text { ma koliko koštao }\end{array}$ \\
\hline & $\begin{array}{l}\text { Moguće pozitivne konotacije } \\
\text { To je sigurno odličan proizvod, pa je red i da više } \\
\text { košta } \\
\text { Nije mi toliko bitna viša cena, jer je servis i } \\
\text { održavanje besprekorno } \\
\text { Ionako retko kupujem i trošim taj proizvod, pa mi } \\
\text { to povećanje baš puno i ne znači za moj budžet } \\
\text { Cene su porasle i drugim sličnim proizvodima, ali } \\
\text { lošijim od ovoga, pa je taj rast očekivan }\end{array}$ \\
\hline \multirow[t]{2}{*}{$\begin{array}{l}\text { Sniženje } \\
\text { cene }\end{array}$} & $\begin{array}{l}\text { Moguće negativne konotacije } \\
\text { Da je taj proizvod valjao do sad bi se i prodao } \\
\text { Očito im ne ide prodaja } \\
\text { Sigurno uskoro ističe rok upotrebe proizvoda, pa } \\
\text { ga se žele čim pre rešiti } \\
\text { Verovatno se na tržištu pojavio novi i bolji } \\
\text { proizvod iste namene } \\
\text { Trgovci su bezobrazno podigli svoje marže, pa ih } \\
\text { sada smanjuju } \\
\text { Trgovac je sigurno pred stečajem, pa rasprodaje } \\
\text { zalihe robe }\end{array}$ \\
\hline & $\begin{array}{l}\text { Moguće pozitivne konotacije } \\
\text { I bilo je konačno vreme da snize te cene } \\
\text { Očito žele povećati promet } \\
\text { To mi je prilika da kupim taj proizvod } \\
\text { To je za očekivati, jer se radi o sezonskom } \\
\text { proizvodu. }\end{array}$ \\
\hline
\end{tabular}

Tabela 1. Percepcija cene proizvoda Izvor: (Gutić, 2009)

Koristeći ovakvu percepciju potrošača mnoge organizacije primenjuju tehniku „psihološkog formiranja cena“. Ova tehnika podrazumeva pažljivu manipulaciju referentnim cenama koje potrošači imaju u vidu kada donose odluku o kupovini.

Efekti psihološkog vrednovanja cena često su suprotni ekonomskim efektima. Ovi efekti podrazumevaju niz taktika formiranja cena (Sudar \& Keller, 1991; Kesić, 1997):

- Postoji tolerancija povećanja cene do određenog nivoa koji neće ugroziti prodaju. Na primer, povećanje cena sa 185 do 200 novčanih jedinica biće bez znatnog negativnog efekta na prodaju, dok će cena iznad 200 izazvati naglo opadanje potražnje. Stoga bi cena, kad god je to moguće, trebalo da se završi neparnim brojem. Cenu od 199,99 potrošač će doživeti kao sto i nešto novčanih jedinica.

- Cena proizvoda s okruglim brojem kao na primer 1000 novčanih jedinica, a ne 999 može stvarati dojam o ek- skluzivnosti tog proizvoda. Na takav proizvod potrošač može gledati kao na visokovredan i prestižan proizvod, pogotovo ako je još uz to lepo dizajniran, upakovan, itd.

- Svaki segment potrošača doživljava cenu na svoj način. Tako, na primer, punije osobe očekuju da će konfekcija za njih biti nešto skuplja od konfekcije koju nosi većina drugih muškaraca i žena (manje serije, zahtevniji krojevi, više materijala, itd). Oni će veće cene takvih proizvoda doživeti kao nešto normalno.

- Ponekad potrošač višu cenu percipira kao nižu i obrnuto. Taj fenomen se objašnjava činjenicom da potrošač zaokružene cene posmatra kao referentne tačke. Tako na primer potrošač cenu od 14.5 percipira kao 4.5 više od 10 , a cenu od 19.5 percipira kao 0.5 manje od 20. Stoga i cenu od 14.5 može percipirati kao višu od 19.5.

- Potrošači često nastoje stvoriti koncept o „poštenim cenama“. To je posebno prisutno kod proizvoda sa izraženom konkurencijom, kao i proizvoda kod kojih mogu objektivno proceniti proizvođačeve troškove proizvodnje. Potrošač sam ocenjuje kolika bi trebala biti cena proizvoda na osnovu prihvaćenih cena konkurentskih proizvoda ili troškova proizvodnje i prosečnog profita. Ukoliko je cena niža potrošač takav proizvod može smatrati kao nedovoljno kvalitetan, a ukoliko je cena viša onda je može percipirati kao nepoštenu (nefer) cenu, što u oba slučaja rezultira nižom prodajom.

- Još jedna taktika za efikasno povećanje cena je „rasčlanjivanje cena“. Organizacije svoje kompleksnije proizvode raščlanjuju na pojedine elemente kojima određuju posebnu cenu, ali tako da ukupna cena ponude bude veća. Jedna od varijanti ovog procesa je da proizvođači razdvoje usluge instalacije i obuke od osnovnog proizvoda i svaku od stavki posebno naplate. U automobilskoj i kompjuterskoj industriji proizvođači nude osnovni model proizvoda (znatno osiromašen) po određenoj prihvatljivoj ceni, ali potrošačima je na raspolaganju dodatni izbor čitavih paketa poboljšanja karakteristika osnovnog modela (dizel motori, auto-klime, električni podizači stakala, panoramski krovovi i sl. u automobilskoj industriji ili razne ponude hard diskova, procesora i softvera u kompjuterskoj industriji) (Jobber \& Fahy, 2006).

Vrlo često potrošači razne akcijske ponude sa smanjenim cenama proizvoda vide kao pokušaj da se firma reši loših prizvoda čija prodaja ne ide. Stoga pojedine firme, u svojim tehnikama prodaje robe, umesto naglašavanja akcijske prodaje po znatno nižim cenama, primenjuju taktike prodaje prošlogodišnjuh modela ili robe sa felerom po nešto nižim cenama. Potrošači u uzaludnom pokušaju traženja greške (felera), nastale u procesu proizvodnje proizvoda, zaboravljaju na percepciju rizika kupovine lošeg proizvoda. Ne pronalaze vidno primetnu grešku, i pod tim utiskom kupuju proizvod zadovoljni njegovom nešto nižom cenom od uobičajne.

Ipak, moramo imati u vidu da se mnogi marketinški faktori uticanja na potrošače poput raznih promotivnih aktivnosti, dizajna, pakovanja, imidža, garancija, servisa i sl., prepliću međusobno sa cenama i umanjuju ili pojačavaju njen uticaj u procesu komunikacije proizvoda i potrošača.

\section{ZNAČAJ INTERNETA I DIGITALNE TEHNOLOGIJE U CENOVNOJ KOMUNIKACIJI SA POTROŠAČIMA}

Tehnološki napredak koji je munjevitom brzinom doneo novu digitalnu ekonomiju stvorio je ogromne poslovne šanse 
ali i probleme stvaranja i zadržavanja konkurentske prednosti. Internet i digitalne tehnologije ušli su u sve segmente privrednog života i mnogostruko promenile obrasce poslovanja. Firme da bi opstale moraju da prilagode svoje konkurentske strategije novim mogućnostima i ograničenjima koje unose ove tehnologije. Internet predstavlja resurs kome mogu da pristupe firme i potrošači širom sveta. Stoga se sve više pojačava intenzitet rivalstva među konkurentskim firmama, prednosti zasnovane na tehnologiji se veoma brzo kopiraju pa je konkurencija sve više orijentisana na cenu.

Značaj cene u sferi interneta se znatno povećao. Navešćemo dva bitna razloga: cene mnogih proizvoda i usluga generalno su postale niže; i percepcija potrošača da niska cena proizvoda znači i njegov loš kvalitet, znatno se promenila.

Internet i digitalne tehnologije uticale su na organizacionu strategiju ukupnih niskih troškova. Ubrzano je prikuplanje informacija i proširen pristup informacijama što je direktno proizvelo uštede na troškovima u svim primarnim i sporednim aktivnostima lanca vrednosti. Organizacije sada mogu da objave hiljade stranica propagandnog materijala sa podacima i informacijama a da ih to ne košta vrlo malo. Male dobavljače, koji su se ranije teško probijali na tržište, sada je lako naći. U distributivnom lancu ukinuto je mnoštvo posrednika. Rivalitet među konkurentima se znatno intenzivirao, sa stalnom tendencijom da se pojačava, otežavajući firmama da se diferenciraju. U nemogućnosti diferenciranja svojih proizvoda i usluga firme pažnjiu potrošača preusmeravaju na cenu. Od takvog unapređenja tehnologije, ipak, najviše koristi imaju kupci. Kupovinom sa samo nekoliko klikova mišem potrošači danas, po vrlo niskim cenama, kupuju proizvode koji su nekada smatrani retkim i nedostupnim, i koje je nekada bilo potrebno tražiti u geografski udaljenim prodajnim objektima. Instalirani su mnogi potrošački sajtovi (info-posrednici) koji za potrebe kupaca pretražuju internet, analiziraju karakteristike sličnih proizvoda različitih proizvođača i prave poređenja nijhovih kvaliteta i cena. Instaliranje uporednih cena doprinosi padu cena čak i kod visokokvalitetnih proizvoda koji su tradicionalno imali premijske cene. Na taj način se dodatno slabi mogućnost firme da razvije jedinstvene karakteristike, a potrošač se isključivo fokusira na cenu. Shvatajući da je ova pojava sastavni deo nove realnosti interneta, mnoge kompanjie svesno učestvuju u pružanju sličnih usluga želeći na taj način ostvariti konkurentsku prednost. One ne zavise od posrednika u kanalima kupovine, okrenute su direktno potrošačima i zahvaljujući mogućnostima potrošačkog fidbeka, slušaju potrošače i reaguju na njihove zahteve. $U$ takvoj situaciji rizik kupovine da jeftina cena znači i loš proizvod postaje sve manji a asortiman i obim kupovine robe putem interneta je u stalnom porastu, čak i kod onih proizvoda na koje potrošač tradicionalno reaguje na osnovu više različitih čula koji se ne mogu direktno preneti putem interneta (čulo dodira, ukusa, mirisa). Rizici te vrste neutrališu se tako što ponuđači i info-posrednici na svoje web sajtove uključuju opcije potrošačkog foruma, putem koga potrošači međusobno komuniciraju, prenoseći tako svoja iskustva o tim proizvodima. Iako kupci ne mogu da opipaju, pomirišu ili probaju proizvod preko interneta, iskustva i svedočenja drugih kupaca mogu izgraditi poverenje kupovine na „nevđeno”. Tako pozitivna iskustva drugih o određenom proizvodu i komparativna analiza njegovih karak- teristika sa sličnim proizvodima stvara poverenje u proizvod, izgrađuje osećaj pripadnosti određenoj grupi i eliminiše rizik kupovine „jeftinih proizvoda na neviđeno” (Dess et al., 2007).

Internet i digitalna tehnologija povećavaju intenzitet rivalstva organizacija, smanjuju mogućnost diferenciranja proizvoda okrećući ključ uspeha prema dobro izbalansiranoj ceni i kvalitetu proizvoda.

\section{ZAKLJUČAK}

Danas se više ne postavlja pitanje da li organizacije treba da komuniciraju sa potrošačima, nego kako i kojim metodama privuči najveću pažnju potrošača da bi postali njihovi stalni i lojalni kupci-advokati. Savremene organizacije pored simboličkog komuniciranja prenošenjem misli ideja i emocija bez prisustva proizvoda, sve više prioritet stavljaju na funkcionalne oblike komuniciranja, koji se obavljaju pomoću elemenata marketinškog miksa i njegovih obeležja. Cena predstavlja moćno sredstvo komuniciranja sa potrošačima posebno kod usluga i proizvoda čiji kvalitet potrošač ne može objektivno da izmeri, pa stoga koristi cenu kao indikator kvaliteta. Potrošači na osnovu cene percipiraju kvalitet proizvoda, imidž firme, ističu svoj željeni status i snobizam ili smanjuju kupovni rizik. Pažljivom manipulacijom referentnim cenama, koje potrošači imaju u vidu kada biraju proizvode, organizacije nameću određeni željeni psihološki dojam potrošaču. Shodno ciljevima komuniciranja proizvođači cene mogu koristiti kao sredstvo diferenciranja proizvoda ili zadovoljavanja informacionih i psiholoških potreba potrošača. Uticaj interneta i digitalne tehnologije još više je pojačao značaj cene kao faktora konačnog donošenja odluke elininišući, raznim metodama fidbeka i potrošačkih foruma, predrasude da sve što je jeftino nije ni kvalitetno. Ipak cena ne sme biti nezavisna od ostalih elemenata marketing miksa. Ona mora biti zajedno sa proizvodom, promocijom i distribucijom uklopljena $\mathrm{u}$ jednistvenu strategiju koja kupcu obezbeđuje izuzetnu korist.

\section{LITERATURA:}

Dess, G., Lumpkin, G., \& Eisner, A. (2007). Strategijski mneadžment. Beograd: Data status.

Gutić, D. (2009.), Ponašanje potrošača, Omiš: Fortunagraf Omiš.

Jobber, D., \& Fahy, J. (2006). Osnovi marketinga. Beograd: Data status.

Kesić, T. (1997). Marketinška komunikacija. Zagreb: Mate Zagreb.

Maričić, B. (2011). Ponašanje potrošača. Beograd: Ekonomski fakultet.

Milisavljević, M. (2010). Strategijski marketing. Beograd: Ekonomski fakultet.

Morno, B. K. (1990). Prining:Making Profitable Decision second edition, McGraw Hill Inc., Nevw York.

Poljić M. (2007). Politika cena u međunarodnom biznisu. Naučni časopis za menadžment, preduzetništvo i liderstvo "Lider“, 3-4, 22-28.

Sudar, J., \& Keller, G. (1991). Promocija. Zagreb: Informator Zagreb. 